\title{
Teacher burnout and opportunities to increase the human resources of urban schools
}

\author{
Lyubov Starostina ${ }^{1 *}$, Valentina Yegorova $^{1}$, Yegor Nikolayev $^{1}$, and Viktoriya Shamayeva ${ }^{1}$ \\ ${ }^{1}$ North-Eastern Federal University the name of M.K. Ammosova, Institute of Psychology, Department \\ of Psychology and Social Sciences, Yakutsk, Russia
}

\begin{abstract}
The article presents a research review on the problem of teacher burnout syndrome and the human resources of general education institutions in connection with the implementation of the Federal State Educational Standard (FSES). Researchers note an increase in the proportion of teaching staff at risk of emotional burnout at work, as well as professional deformations of the teacher's personality. The article substantiates the relevance of consideration of management issues related to the development of the human resources of educational institutions through the prism of effective interaction of managers with the teaching staff and the teacher's personality in the context of preventing their emotional burnout. The abundance of research on the problem of burnout indicates the continued interest of scholars of humanities and natural sciences for quality of life, psychological health, personal and professional development of teachers of general education schools designed to act as carriers of new ideas and innovative technologies, the moral and socioeconomic transformation of society. The authors consider the concepts associated with the development of human resources, making the main emphasis on the role of the human factor, and the reserves of the teacher's personality, propose to create a kind of Internet platforms in each city, namely, virtual pedagogical sites as an alternative to motivating pedagogical creativity, as well as offer systematization of various burnout factors and prevention measures.
\end{abstract}

Keywords: Education, human resources, emotional burnout.

\section{Introduction}

Russian education is at the epicenter of transformations in the rapidly changing contemporary world. This is associated with intense processes of forming the legislative framework of management structures, with the implementation of innovative approaches to its various aspects, which makes the education system completely dependent and controlled. Thus, the entire system of relations between the state and education is being radically restructured, with the role of federal legislation and the corresponding requirements for the activities of educational institutions being strengthened. The transition of educational institutions to a new system of relationships determines the formation of a

\footnotetext{
* Corresponding author: lyudmira@inbox.ru
} 
new personnel policy, as the most important management problem. This raises the challenge of developing corporate policy in each individual institution, which, in turn, includes managerial, innovative, information, and human resources capabilities.

Managerial capability is understood as the effectiveness of the entire education management system. The amount of scientific and technical achievements used in the teaching process determines the innovative potential of the school. The effective transmission and circulation of information depend on the information potential. Finally, the human resources potential depends on the qualification level and creative abilities of teachers [1].

The concept of human resources means not just employees of the organization but assumes also active subjects of professional activity. This indicates the importance of professional qualifications when employees possess not only the appropriate education and training for work but also certain personal qualities, enhanced by the acquisition of professional experience. Thus, human resources can determine the effectiveness, efficiency, and competitiveness of the entire organization.

Certainly, the human resources are determined by the human factor, which is understood as the personal potential and resources of a particular person driven by a system of moral and spiritual values, motivation, and self-esteem. Personal fulfillment of the employees determines what goals and objectives they can implement in professional activity in the future. Psychological resources of a person directly depend on physical and psychological health, namely, performance, stress resistance, and abilities. Also, the psychological resources of the individual include a sense of responsibility, conscious maturity, and the significance of identification with corporate values.

The concept of development of education of the Russian Federation until 2020 envisages creating a contemporary system of continuous education, training, and retraining of professional personnel (the Decree of the RF Government of 17 November 2008)[2]. This document recognizes the importance of management decisions in the capacity building of educational institutions through the implementation of a continuous education system, involving training and retraining of teaching staff according to the challenges of the new cultural and historical time and scientific and technological achievements of mankind.

Thus, the present research shows the importance of managerial decisions in the formation of human resources, which brings the human factor in the development of the organization to the fore. It is the person, the employee's personality, their professional and personal qualities and the capabilities of their creative implementation in the profession, their technological ability that can determine the socio-economic development of a municipality, region, and the state in general [3].

In this article, the authors consider an urgent psychological problem that is not taken into account in the real practice of relationships in the teaching staffs of educational institutions, namely, the burnout syndrome of teachers, and ways to overcome this problem, as this is seen in the modern context of the implementation of new FSES into the education system.

\section{Research review and analysis}

During the implementation of FSES, the risk of professional burnout among teachers increases. The growth of professional load, control, and requirements for the qualification and competence of the teacher, and for his personal professionally important qualities, as well as involvement in the implementation of new FSES, lead to emotional overload which often cannot be compensated by personal resources. At that, the very conditions of professional activity act as stressors. These involve changing management level, reorganizing an educational institution and the specifics of organizational processes, the 
fear of cuts, and lack of demand, which cause a long-term stress response of the teacher's personality $[4,5]$.

The burnout in school teachers is gradual:

- the first phase is characterized by a gradual decrease in positive emotional experiences, along with increased anxiety, and blunting of feelings;

- the second phase is manifested in a decrease in interest in work, symptoms of somatic disorders (headaches), loss of strength and energy during the working week, as well as irritability;

- and the third phase is actually mental burnout, loss of desire to work, and emotional exhaustion [6].

Back in the $80 \mathrm{~s}$, it was revealed that the teaching profession was the most emotionally loaded, and there were many more emotional burnout factors compared to other professions. The volume of an hour's weekly workload always exceeded the established norm for other types of professional employment [7].

Summarizing the research of various authors, one can note their close connection with the quality of life of teachers, highlighting socio-economic, organizational, sociopsychological [8-13], and individual typological factors [14].

Socio-economic factors:

- mismatch of salary with the effort;

- psychoemotional tension in the teaching staff;

- lack of opportunities for self-expression and self-actualization (due to the lack of financial resources);

- fear of losing the job due to constant optimization in human resources management;

- level of education: teachers with higher professional education are less likely to burn out than teachers with secondary professional education since higher education provides individuals with broader opportunities to solve emerging problems in their professional activities;

- record of work, lack of normal working conditions, the salary that does not correspond to efforts and individual returns, inability to pay and go to advanced training courses;

- skill level: the higher the category is, the fewer burnout symptoms are.

Organizational factors:

- inefficient management of the workforce;

- large variation in the nature of the work performed, blurred functions, and unclear job descriptions;

- dissatisfaction with the organizational processes of labor.

Socio-psychological factors:

- difficult contingent of pupils and parents with whom the teacher communicates;

- distrust and conflicts with school administration;

- psychoemotional tension with co-workers;

- lack of time for communication in their own families.

Individual typological factors, such as temperament, extroversion-introversion, neuroticism, situational and personal anxiety, self-awareness, self-organization, readiness for teamwork, emotional stability, and personal resources can also become a favorable ground for the development of burnout syndrome:

- lack of positive motivation for the profession;

- excessive experience of negative events, emotional rigidity;

- excessive psychoemotional stress;

- perfectionism, excessive zeal; continuing to perform work functions outside school hours.

It is empirically proven that at a moderate level of sensitivity and lability, burnout does not occur, while the combination of anxiety, aggression, and introversion triggers emotional 
burnout. Failure to respond to negative impulses promptly increases painful experiences, leading a person to psychosomatic disorders. A trait, such as spontaneity, is associated with personal detachment, and rigidity is associated with psychotraumatic, stressful situations. Aggressiveness as a personality trait is more strongly correlated with burnout. The authors of the research note that almost all teachers manifest medium and high levels of emotional burnout, and therefore it is necessary to practice preventive measures to avoid burnout [15, $16]$.

The risk of developing professional hazards that reduce the quality of professional activity of teachers increases every year. The teacher's work is complex and requires qualities, such as humanity, tolerance, as well as continuous professional development, a broad outlook, and systematic thinking [17]. Studies indicate the need for preventive measures for burnout syndrome in educational institutions [18, 19].

To prevent emotional burnout and professional hazards, the above-mentioned authors provide the following recommendations, which authors of the present study divided into two blocks:

Emotional-volitional regulation:

- the ability to cope with negative states;

- emotional stability in ambiguous, conflict situations;

- correction of maladaptive personal attitudes;

- correction/therapy and ability to plan their life;

Increasing awareness (involvement in professional activities):

- self-knowing, personal reflection;

- sensitivity and responsibility;

- the ability to manage their time, distribute their loads, be able to switch and vary the performance of different types of work.

- developing empathy as a more conscious intellectualized perception of the experiences and feelings of others.

\section{Conclusion}

Summing up the analysis of the literature, it can be noted that the abundance of research and various authorial approaches and classifications of burnout syndrome is due to the influence of a large number of factors that cause it. So, the authors have presented only a part of a large array of studies on the problem of burnout in the education system, highlighting the influence of socio-economic, organizational, socio-psychological, and individual typological factors.

However, only an approach to considering the problem of human resources through the prism of professional burnout of teachers will provide a solution to many organizational and managerial problems facing contemporary education. Under the stressful conditions that accompany the teaching activities of Russian teachers, effective management by the school administration plays an especially important role. Personal and professional qualities of principals, their awareness of the style and methods of managing the team, their focus on the development prospects of the organization, an unbiased, creative, team-based approach to management decisions, a reasonable distribution of responsibilities, etc. can increase the motivation and internal employee pool of the school teaching staff. Besides, the desire for personal growth and interest in solving problems can also have a positive effect on the teacher's well-being, thereby eliminating professional reduction.

The proposed systematization of the various factors of burnout requires further in-depth study in the development of professiogram of contemporary teachers considering their pedagogical activities, the specificity of disciplines, and socio-cultural space. To motivate pedagogical creativity, the authors offer to create unique online communities in each city, 
namely, virtual pedagogical sites for free discussion of typical and atypical problems of pedagogical work, exchange of professional experience in the format of pedagogical life hacks.

At that, the organization of such platforms may involve the relevant departments of municipal authorities, as well as methodological associations of psychologists. Such a platform has all the opportunities for further growth and development, providing the creation of additional interacting platforms for all participants in the educational process.

Thus, to form competent human resources policies it is necessary to consider not only the so-called successfulness of teachers but also adjust and develop the leadership style of the school administration, taking into account the problems of emotional and mental overload.

\section{References}

1. M.V. Kudrina, Gosudarstvennoye upravleniye. Elektronnyy vestnik, 22, 3 (2010)

2. Order of the Government of the Russian Federation of November 17, 2008 N 1662-r On the Concept of long-term socio-economic development of the Russian Federation for the period until 2020 (with amendments and additions) (Base-Garant, 2020), Available at http://base.garant.ru/194365/\#ixzz3qWk223ae (last accessed date 30.12.2020)

3. P.V. Zhuravlev, M.N. Kulapov, S.A. Sukharev, World experience in personnel management. Review of foreign sources: monograph (Russian economics academy, Moscow, 1998)

4. R.A. Abdurakhmanov, O.V. Glebskaya, Human capital, 11-2(119), 198-208 (2018)

5. A.V. Mordovskaya, Z.N. Platonova, Mezhdunarodnyy studencheskiy nauchnyy vestnik, 5-1, 39-41 (2016)

6. V.V. Meletichev, S.M. Shingayev, Motivation of professional activity and professional burnout of teachers: theory, diagnosis, relationship, prevention: monograph (St. Petersburg Academy of Postgraduate Pedagogical Education, St.Petersburg, 2014)

7. L.F. Kolesnikov, Reserves of the pedagogical work efficiency (Nauka, Novosibirsk, 1985)

8. I.A. Kurapova, Socio Time, 4(8), 135-146 (2016)

9. M.V. Smagina, Yu.S. Kuzubova, Development of modern education: theory, methodology and practice, 1(11), 62-65 (2017)

10. D.N. Pogorelov, Nauchnoye obespecheniye sistemy povysheniya kvalifikatsii kadrov, 2(35), 78-85 (2018)

11. U.Sh. Magomedkhanova, Emotional burnout of primary school teachers as a psychological problem, in Collection of materials III International Scientific and Practical Conference "The Teacher Creates a Nation”, 20 November 2018, Groznij, Russia (2018)

12. V.V. Kisova, O.A. Katushenko, Mezhdunarodnyy studencheskiy nauchnyy vestnik, 5, 108 (2017)

13. Ye.A. Trukhan, P. A. Parkhimovich, T. O. Budko, Bulletin of Omsk University. Series Psychology, 3, 40-47 (2019)

14. T.F. Bazylevich, Psychology of an integral individuality. Key ideas. (Kogito-Center, Moscow, 2018) 
15. M.B. Kotova, V.B. Rozanov, Ye.I. Ivanova, Cardiovascular therapy and prevention, 17(S), 9b-10a (2018)

16. V.I. Dolgova, G.G. Goleva, A.A. Kunilova, Modern High technologies, 8(1), 106-110 (2016)

17. I.K. Shats, The Bulletin of Leningrad State University named after Alexander Pushkin, 5(3), 49-57 (2013)

18. Ye.A. Kilpa, I. I. Kakadiy, Discourse, 11(13), 78-83 (2017)

19. M.B. Kotova, V.B. Rozanov, A.A. Alexandrov, Ye.I. Ivanova, Voprosy psikhologii, 2 , 67-79 (2017)

20. Ye.S. Morozova, Science Time, 10(22), 264-271 (2015) 